\title{
Ser Terena, professor e liderança indígena: minhas histórias, minhas memórias
}

\author{
Maioque Rodrigues Figueiredo ${ }^{1}$
}

DOI: http://dx.doi.org/10.20435/tellus.vi43.715

Indígena da etnia Terena, graduado em Normal Superior pela Universidade Estadual de Mato Grosso do Sul (UEMS), Campo Grande, MS, 2010; especialização em Cultura e História dos Povos Indígenas pela Universidade Federal de Mato Grosso do Sul (UFMS), Campo Grande, MS, 2015; mestre em Educação pela Universidade Católica Dom Bosco (UCDB), Campo Grande, MS, 2017; graduando em História pelo Centro Universitário Leonardo da Vinci (UNIASSELVI), Campo Grande, MS, 2020. Aprovado no concurso público para professores no ano de 2018. Liderança e professor efetivo na escola pública no ensino fundamental da Escola Municipal Indígena Cacique João Batista Figueiredo, da Aldeia Tereré, Terra Indígena Buriti, Sidrolândia, Mato Grosso do Sul. Coordenador pedagógico contratado na rede estadual de educação da SED/MS, da Escola Estadual "Kopenoti" de Ensino Médio Prof. Lúcio Dias - extensão Flaviana Alcântara Figueiredo, Aldeia Tereré, Terra Buriti, Sidrolândia, MS.

Meus primeiros passos e caminhos percorridos, caminhos que parecem não ter fim, por onde andei, o que vi e li a respeito. Entre mudanças e resistência, a minha identidade já possui um repertório híbrido. Sou Terena, os ditos excluídos da sociedade, os subalternos, colonizados, oprimidos. Pois nesse caminho conturbado, ainda não concluído, posso dizer que não sou mais a mesma pessoa, sou outra, em uma palavra resumo tudo o que estou sentindo, me sinto libertado. Essa narrativa é construída a partir daquilo que me tornei, daquilo que consigo enxergar, onde estou situado, de onde falo.

Pois sou parte da construção dos sonhos desse povo, que por séculos foram submetidos à imposição colonial ocidental, é a partir desse entendimento que é o meu ponto de partida. Undy (na língua Terena, pronome da primeira pessoa

\footnotetext{
${ }^{1}$ Universidade Católica Dom Bosco (UCDB), Campo Grande, Mato Grosso do Sul, Brasil.
} 
do singular "eu") Maioque Rodrigues Figueiredo, undy kopenoty (índio) Terenoé.

Nasci em Campo Grande, capital de Mato Grosso do Sul. Segundo a minha mãe, tive complicações no meu nascimento, no momento do parto, pois algumas irmãs que trabalhavam naquele hospital acharam por bem me batizar, o batismo poderia me curar naquele momento e me deram o nome de José Maioque; porém, ao eu ser registrado em cartório, o primeiro nome não foi registrado. As pessoas de mais idade da aldeia me chamam de Zé ou Zé Maioque, inclusive os meus irmãos, os amigos que fui construindo me chamam de Maioque, pois não estranhe se alguém me chamar de Zé.

Nasci dentro de uma família tradicional Terena da Terra indígena Buriti, município de Dois Irmãos do Buriti, Mato Grosso do Sul (MS), meus avós paternos e avós maternos falavam a língua Terena e seguiam à risca os costumes e a tradição Terena que são remanescentes do povo Aruák.

Lembro que minha avó Flavia Alcântara, mãe de meu pai Joaquim Loureiro Figueiredo Neto, se lembrava das histórias do Exivá, eu construía esse lugar na minha imaginação. Segundo minha avó, era um lugar com muita fartura, tinha muita caça, pesca, mel, tinha muita roça, a mãe dela tinha vindo de lá do Exivá. Minha avó era uma excelente tecelã, fabricava colchas, mantas, redes de algodão e lã. Às vezes ficava o dia todo com ela tecendo lã, tinha uma peça que ela mesma fabricava, chamada cambito, esse servia para fabricar os fios de lã ou de algodão. A lã era fixada ou amarrada na base do cambito, outro fazia o movimento de girar o cambito - no caso, eu e meus primos; a minha avó ia conduzindo e firmando a Iã, os fios iam sendo fabricados e ficavam cada vez mais compridos, enrolávamos os fios na base do cambito, às vezes ficava bem pesado. O trabalho dos meninos era girar o cambito, para as meninas ficava o preparo das lãs. Lembro também que ela fabricava pote de barro, esse servia para armazenar água, lembro-me do cheiro gostoso da água, era tudo muito natural.

Meu avô João Batista Figueiredo, pai de meu pai, era uma pessoa extraordinária, falava pouco o português, foi Capitão (termo usado para definir a representação política da aldeia indígena) na Aldeia Buriti, era um koéxomoneti (Terena que adquiriu experiências ao longo da vida e domina os fenômenos da vida, da natureza e da espiritualidade) ou "pajé", líder espiritual muito conhecido e respeitado na região, pois dominava os conhecimentos místicos, 
espirituais e da natureza. Conheci e convivi com meu avô, presenciei muitos trabalhos realizados por ele.

Era muito constante a presença de pessoas de todos os lugares da região, inclusive pessoas de outros estados vinham em busca de resolver seus problemas de saúde, muitas vezes desenganados pelos médicos. Lembro-me de alguns rituais feitos por ele:

1. O canto com o porungo feito de cabaça onde passavam horas cantando, parecia que o koixomonéti estava dialogando com alguém que só ele enxergava, esse parecia estar trazendo alguma mensagem espiritual do paciente. Se a alma dele estivesse longe, o ritual seria mais longo, seria preciso mais canto para trazer a alma de volta; se a alma estivesse perto, o ritual seria menos longo.

2. Outro ritual era chamado de "benzer" ou "dar passe", semelhante a uma oração, com uma voz bem suave e piano, esse ritual era constante mesmo que as pessoas não tivessem nenhum tipo de doença, ou também para crianças com quebrante, ou crianças que choram muito a noite, o ritual também era feito contra picada de cobra, dor de dente, dor de cabeça.

3. O ritual das ervas medicinais, pois João Figueiredo conhecia muito o poder das ervas, coletava e fazia chá para vários tipos de doenças.

Outros conhecimentos tradicionais que dominava eram sobre os fenômenos da natureza, nas rodas de conversar ele dizia que tudo na natureza tem dono, a mata tem dono, a água tem dono, os animais têm dono, e cada um desses tem a sua importância para a natureza e para as pessoas. Meu avô dizia que a natureza conversa com a gente, se entendermos ela, ela nos tramite muitas informações, como por exemplo o canto dos pássaros, o vento, a lua, o sol pode agir sobre nós. Para extrair matéria-prima da mata, é preciso respeitar a fase da lua.

Meu avô João Batista Figueiredo, koéxomonéti, um Terena autêntico que ao longo da vida soube compreender a arte de viver, Terena que adquiriu experiências ao longo da vida e dominou os fenômenos da vida, da natureza e da espiritualidade. 
Meu avô João Batista Figueiredo contava muitas histórias do cotidiano, da sua experiência como capitão e dos trabalhos realizados como pajé. Os conhecimentos tradicionais, as sabedorias e os conselhos dele como capitão e pajé eram lei para as famílias Terena, as pessoas que conviveram com ele na época seguiam à risca os conselhos que ele falava, principalmente a questão relacionada à crença e à cosmovisão indígena.

A convivência com meus avôs maternos foi pouca, mas lembro das histórias do cotidiano dos meus avôs, minha avó Antonia e meu avô Silvério, pais de minha mãe Rozinha Mamedes Rodrigues Figueiredo, eles relatavam muito sobre os trabalhos nas fazendas nas proximidades da Terra Buriti.

Meus avós maternos tiveram nove filhos, oito homens e uma mulher, todos criados na roça, plantavam de tudo naquela época, arroz, feijão, mandioca, criavam muita galinha, porco. Lembro também que tinha muito peixe no córrego Buriti. Atualmente, muitos filhos dos meus avôs moram na aldeia urbana Tereré, em Sidrolândia, e a maioria trabalha nas empresas. A minha mãe, única mulher entre oito irmãos homens, segunda mais velha, ela tinha que dar conta de cuidar de todos os irmãos mais novos, que eram muitos.

Segundo relatos de minha mãe, ela lavava roupa na beira do córrego Buriti, que passava bem perto da Aldeia Barreirinho, ao mesmo tempo em que lavava roupa, também nadava e pescava, até hoje os meus tios ganham o apelido de lambari, porque dizem que nadavam igual peixe.

A minha mãe é um exemplo de pessoa, um exemplo de companheira e amiga, pois ela estava presente em todos os momentos de nossa vida familiar. Com ela, mesmo longe de nosso povo, ela nos contava as história dos Terena, mamãe também era falante da língua Terena. Deixo aqui todo meu carinho e respeito pela minha querida Mãe, que partiu feliz, pois ela queria ver seus filhos formados. Mamãe estava entre a vida e a morte no hospital, quando estava marcada a entrevista do processo seletivo de mestrado na UFMS em Campo Grande, priorizei estar junto de minha mãe, porque nunca mais iria vê-la.

Ainda pequeno, ali aos três, quatro anos de idade, fui morar na Aldeia Porto Lindo, povo Guarani, no município de Japorã (MS). Ali cresci até a idade de ir para escola, minha infância foi no meio do povo Guarani, onde aprendi a falar um pouco a língua Guarani. Lembro que fui criança pra valer, brinquei muito, fui 
muito feliz na minha infância. Meu pai era enfermeiro da Fundação Nacional do Índio (FUNAI), ele concluiu o quarto ano dos anos iniciais, ele é muito inteligente, é falante da língua Terena e aprendeu também a falar a língua Guarani. Como enfermeiro da FUNAI, não deixou faltar nada pra mim e minha família.

A minha vida na Aldeia Porto Lindo está guardada na memória, cada momento, fui muito feliz ali naquela aldeia, brinquei, nadei, passeava a aldeia toda, lembro que tinha muitos rios, cachoeiras, matas, muitas árvores frutíferas. Eu gostava de colher frutos na mata, como a jabuticaba, era nativo ali naquele lugar, armava arapuca, jogava bola, tenho saudade e ainda quero retornar para rever os amigos que ali construí.

Aos sete anos de idade, entrei na escola, lembro que chamava a nossa escola de "missão", a escola ficava em uma chácara, com muitas plantações, árvores frutíferas, tinha também igreja, naquela época a escola ficava fora da aldeia, lembro que íamos de charrete, às vezes íamos a pé.

Lembro que foi um desastre a escola na minha vida, estava perdido, não entendia o que a professora falava, parece que queriam me alfabetizar na marra, eu não conseguia ler, lembro que até ficava de castigo, porque a professora explicava e, quando chegava a minha hora de ler, não saía nada. Meu pai ficava sabendo, já me dava uns puxões de orelha; tabuada nem se fala, meu Deus, como era difícil, e assim foi o primeiro e o segundo ano na escola. Nesses meios lembro que viajava para visitar meus avós maternos e paternos nas férias na Aldeia Buriti.

Meu pai foi transferido para a Aldeia Cachoeirinha, município de Miranda, MS, outra escola, todos os alunos falavam a língua Terena, não entendia nada, nem na escola nem fora da escola; dos professores, lembro que era uma professora não indígena. Ali na Aldeia Cachoeirinha, por conta da língua, não fiz tanta amizade. Novamente, meu pai foi transferido.

Fomos morar na Aldeia Jaguapiru, município de Dourados, MS, território do povo Guarani Kaiowá e Terena. Ali fiz muitas amizades, também estudei na escola da aldeia, tinha professores indígenas e não indígenas, acho que já um pouco crescido já prestava atenção nas explicações dos professores, terminei a terceira série e, novamente e definitivamente, meu pai foi transferido para a recém-criada Aldeia Tereré, município de Sidrolândia, MS, no ano de 1985. 
A minha avó Flaviana Alcântara Figueiredo e meu avô João Batista Figueiredo, até por influência que eles tinham na época com o coordenador da FUNAI em Campo Grande, MS, pediram que meu pai fosse transferido pra recém-criada Aldeia Tereré, que estava precisando de um enfermeiro.

Nesse período, eu tinha meus dez anos de idade e fui matriculado em uma escola na cidade, muito conhecida, Escola Municipal Olinda Brito de Souza. Nessa escola me parece que eu já estava bem situado no mundo escolar, lembro que, na quarta série, a escola promoveu um concurso de tabuada e eu ganhei, ficando em primeiro lugar; o meu irmão foi campeão de embaixadinha, ele estava na terceira série.

Em meio a esses entrelugares, fui construindo minha identidade, a maior parte da minha infância foi no meio povo Guarani, vivi Guarani, brincava Guarani, dançava Guarani, cantava Guarani, porém, ao dormir, a minha mãe me contava histórias Terena.

Parece que não íamos mais mudar, era definitivo viver na Aldeia Tereré em Sidrolândia, MS. Meu pai, servidor da FUNAI, realizava os casamentos dos indígenas, já não fazia só a função de enfermeiro, pois era atribuído também o papel do chefe de posto, registrar nascimento e casamento de índio no livro de registro da FUNAl; cresci vivenciando isso, de vez em quando meu pai pedia para que eu o ajudasse, cresci lendo e decorando a Lei 6.001, de 19 de dezembro de 1973, o Estatuto do Índio. Isso pra mim era magnífico, nem sabia o que significava. Mas estava ali ajudando meu pai, ajudando meu tio Cacique da Aldeia Tereré João Figueiredo Filho, popular Capitão Santo.

Ajudar meu tio, Capitão Santo, com os trabalhos da Aldeia, e meu pai Joaquim Loureiro Figueiredo Neto, com os trabalhos que não eram só a função de enfermagem, mas também outras atribuições, foi importante para a minha formação e entendimento sobre a questão indígena, foi ali o início do meu envolvimento com a questão indígena, a construção da minha identidade, defensor da causa indígena, mesmo sem saber o que estava acontecendo, mesmo sem ter uma leitura de sociedade, eu já estava ali trabalhando, fazendo documentos, tudo era eu, aí não parei mais.

Na Aldeia Tereré, lembro que eu gostava muito de jogar futebol, fiz muita amizade por conta do futebol, saía pra jogar fora representando a cidade, sonhei 
em ser jogador de futebol, e por aí vai. Terminei o ensino fundamental na Escola Estadual Sidrônio Antunes de Andrade, fiz também o primeiro ano do segundo grau.

Também estudava música, eu era contratado pela Banda Musical de Sidrolândia, era percussionista, apresentamos e ganhamos títulos estaduais e nacionais em concursos de bandas musicais. Aos dezoitos anos de idade, saí da banda musical, tirei a carteira de trabalho e fui trabalhar na construção do frigorífico, indústria de alimento Agro Eliane. Ao terminar a construção do frigorífico, passei a trabalhar na linha de produção. Trabalhei um ano e meio, e saí, acho que indignado com a situação, meu chefe de setor tinha apenas a terceira série do ensino fundamental, a indústria estava recém-começando, e as oportunidades que iam surgindo sempre eram dos não indígenas que iam preenchendo os cargos.

Ainda sem concluir o ensino médio, já com vinte anos de idade, Deus me abençoou com o casamento. Nesse período, parei de estudar, pois tinha que trabalhar, eu tinha uma família pra sustentar e não tinha nenhuma formação. Meu filho nasceu e eu, desempregado, fui trabalhar na usina Santa Olinda, uma indústria de açúcar e álcool, em Sidrolândia, pois ali trabalhei três meses, não foram nada fáceis, entre febre e dores no corpo, mãos calejadas, estava findando a safra no mês de dezembro. Aí a reflexão: não vou aguentar, o salário não vai dar conta da manutenção da família; para completar, morava na cidade pagando aluguel.

Após a reflexão, estava decidido a voltar a estudar, pois estava convencido de que através dos estudos poderia ter melhores oportunidades. Não lembro como, mas sei que meu nome estava inscrito na segunda turma do Magistério Indígena. Fui estudar na Escola Pe. Félix Zavattaro, Curso de Formação e Habilitação de Professores de 1a a 4 a Série do 1 o grau para o contexto indígena, onde concluí o curso de 2 o grau no ano de 1999. Para mim, uma oportunidade única, o convívio e a experiência com outras pessoas de comunidades Terena e outros grupos étnicos que compõem o estado de Mato Grosso do Sul e Mato Grosso contribuíram muito para minha compreensão da diversidade linguística, cultural e de ideias. Porém, não atuei na educação.

Nesse tempo, ainda não existia a escola Cacique João Batista Figueiredo, e sim um projeto "Curso de Ensino de Língua Terena", através da Portaria n. $003 / 11 / 95$. A primeira professora que atuou nesse projeto foi a professora Maria de Lourdes, a princípio como professora de língua Terena, natural da Aldeia Cachoeirinha, município de Miranda, MS. 
Minha primeira experiência como professor foi nos anos de 1997 e 1998. Depois, por questões internas, nos próximos seis anos não atuei mais na sala de aula. Fui trabalhar em outros espaços, manutenção de aviários, entre outros serviços, sem carteira assinada.

Em 2002, trabalhei na indústria de confecção de vestimenta como mecânico e eletricista em Sidrolândia, em 2003 prestei vestibular pra área de administração na UEMS, em 2004 era acadêmico de administração, em 2005 e 2006 voltei pra sala de aula como professor na Escola Extensão Cacique João Batista Figueiredo.

No mesmo ano, prestei vestibular para o curo de Normal Superior, porque no próximo ano não poderia mais voltar pra sala de aula, os professores teriam que estar cursando o curso superior na área de educação. Porém, mesmo iniciando o Normal Superior, já não tinha mais a vaga para minha lotação na escola, por motivo de priorizar outros professores, fiquei de fora.

Não perdi a esperança, fui para a Aldeia Barreirinho, Terra Indígena Buriti, município de Dois Irmãos do Buriti, pois esta comunidade estava recentemente criando e construindo a Escola Silvério Rodrigues Mamedes, que me recebeu de braços abertos. Ali trabalhei por quatro anos, e ao mesmo tempo cursava o Normal Superior. Foi uma grande experiência, desenvolvi bons trabalhos na sala de aula, também era visto como uma liderança. Conclui o Normal Superior em 2010.

Em 2011, fui convidado para trabalhar na Secretaria de Assuntos Indígenas do município de Dois Irmãos do Buriti. Uma das primeiras secretarias municipais já criadas no Brasil. Pais de alunos não queriam que eu deixasse a sala de aula, era uma resposta e resultado do bom trabalho que desenvolvi na Aldeia Barreirinho. Neste momento, a Terra Indígena Buriti já estavam em processo de retomada das terras tradicionais.

No mesmo ano fiz inscrição como aluno especial no Curso de Pós-Graduação de Mestrado em História, da Universidade Federal da Grande Dourados (UFGD), Dourados, MS, e concluí a disciplina de Antropologia do Colonialismo. Curso que me orientava mais ainda sobre a história dos povos indígenas. A luz da militância indígena ficava cada vez mais acesa.

Ainda no final do segundo semestre de 2011, fui convidado pela comunidade da Aldeia Tereré, Terra Indígena Buriti, para assumir o cargo de Cacique. Neste momento, estava prestes a encarar um conflito interno, me sentia preparado para 
tal embate, não só com os conflitos internos, mas com os problemas externos e principalmente político-ideológicos.

Foi um ano de embates, sem nenhum prestígio político em Sidrolândia, não me contrataram, era mais um professor formado fora da sala de aula por conta dos interesses políticos naquele momento.

A comunidade sempre me dando força, pois estavam confiando na minha visão social e política, precisávamos estar bem politicamente para que pudéssemos dar os próximos passos. Em 2013, fui contratado para trabalhar na assessoria do gabinete do Prefeito em Sidrolândia, colocamos os projetos em prática, principalmente na área de educação e território.

Pois bem, os estudos me proporcionaram coisas boas, mas também problemas, digo coisas boas no sentido de ter oportunidades para o mercado do trabalho, trabalhei como professor por um curto período, e na gestão da política publica municipal em Dois Irmãos do Buriti e Sidrolândia. Digo problema porque é no campo político que as tensões de conflitos ideológicos acontecem. Os estudos me fizeram ver a sociedade, e vi que os povos indígenas foram vítimas da sociedade colonizadora; no começo, tinha essa visão fragmentada, e ao longo dos tempos e através dos movimentos e estudos fui aumentando a minha visão de sociedade, principalmente sobre a história dos povos indígenas.

Nesse momento, também consolidava cada vez mais a construção da minha identidade enquanto militante do movimento indígena.

\section{Sobre o autor:}

Maioque Rodrigues Figueiredo - Mestre em Educação pelo Programa de Pós-Graduação em Educação (PPGE) da Universidade Católica Dom Bosco (UCDB). Indígena da etnia Terena. Professor na Escola Municipal Indígena Cacique João Bastista Fiqueiredo, da Aldeia Tereré, Terra Indígena Buriti, Sidrolândia, Mato Grosso do Sul. E-mail: maioque.indi@hotmail.com, ORCID: https://orcid.org/0000-0001-9497-7717

Recebido em: 11 de julho de 2020.

Aprovado para publicação em: 3 de novembro de 2020. 
